\title{
Our New Editor for Western Europe Norberto Masciocchi
}

In December, I announced that Professor Dr. Norberto Masciocchi will replace Dr. Jan W. Visser as the Editor for Europe for POWDER DIFFRACTION. In this editorial, I will introduce Dr. Masciocchi to our readers and also announce that Dr. Jaraslav Fiala has accepted the position as Editor for Eastern Europe.

Dr. Masciocchi began his career in single crystal crystallography with a thesis on metal carbonyl clusters containing interstitial atoms at the University of Milan in 1988 where he received his PhD (Dottorato di Ricerca). In 1985 and again in 1989, he was a Visiting Scientist at the IBM Almaden Research Center, in San Jose, California. At IBM, he developed the use of synchrotron radiation in powder diffraction working under the supervision of William Parrish and Michael Hart. This work included structural studies of some ionic compounds and organic polymers, instrumentation, measurements of anomalous scattering, texture in thin metallic films, and microstructural characterization of powdered metallic catalyst with different thermal histories. In 1987 he also spent two months at Kernforschungsanlage, $\mathrm{KFA}$, in Julich, Germany where he developed tools for combined analysis of materials by both synchrotron and neutron diffraction working with Gerog Will.

From 1990 to the present, Dr. Masciocchi has been at the University of Milan where he holds a research assistant position. He is still continuing conventional single crystal studies and is deeply involved in the promotion and development of the ab-initio structure solution method in X-ray powder diffraction using in-laboratory data collection. This development is applied to studies of coordination compounds and organometallics that fail to produce suitable single crystals. In 1995, he organized the symposium "Giornate di Studio sulla Diffrattometria a raggi X da Materiali Policristallini. Il Contributo della Diffrazione a Polveri alla Cristallografia Strutturale: Tecniche Rietveld ed ab-initio" that was well attended. He edited the proceedings of this meeting that were in English.

His latest efforts have lead to identify, in the coordination and organometallic realm, the area potentially suitable to the application of XRPD as a structural tool. Categories include insoluble, thermally unstable compounds which cannot be recrystallized from the melt; metastable phases destroyed or modified on manipulation; twins, particularly twin-lattice quasi- symmetry twins, where the twinning makes the single crystal sampling of reciprocal space inappropriate; and gas/ solid, liquid/solid, and solid-state reactions fragmenting and misorienting the coherent domains of the starting crystals but conserving the polycrystalline nature of the sample. A review of these studies has been published as a Dalton Perspective: Masciocchi, N. and Sironi, A. (1997) J. Chem. Soc., Dalton Trans., 4643.

The correct address for Dr. Masciocchi is:

Dr. Norberto Masciocchi

Dipartimento di Chimica Strutturale e Stereochimica

Inorganica

Universitá di Milano

Via Venezia, 21

20133 Milano, Italy

Phone: +39-2-70635120

FAX: +39-2-70635288

E-mail: norbert@csmtbo.mi.cnr.it

Our new Editor for eastern Europe is Dr. Jaraslav Fiala. His address is:

Dr. Jaraslav Fiala

SKODA Research Ltd.

31600 Plzen, Czech Republic

Phone: 42019-773-4335

FAX: 42019-773-3889

E-mail: jaraslav.fiala@vsb.cz (one week each month)

Authors based in Europe should now send all manuscripts for processing to one of these editors. You decide where the boundary lies between east and west. There are no strict rules for this journal.

Dr. Fiala will be featured in the June editorial. 